\title{
Licencias Creative Commons: licencias de libre acceso y su funcionamiento
}

\author{
Creative Commons licenses: free access licenses and their operation
}

\author{
Edna J. Maradiaga.
}

Médica, Maestría en Salud Pública; Unidad de investigación Científica, Facultad de Ciencias Médicas Universidad Nacional Autónoma de Honduras, Tegucigalpa.

La Revista Médica Hondureña (RMH, https://revistamedicahondurena.hn/) ha implementado en los últimos años una serie de estrategias que llevan a cumplir criterios de calidad y periodicidad que se necesitan para ser incluida en varios índices internacionales, bases de datos, portales y repositorios como CAMJOL, Latindex-catálogo, Amelica, Scielo, entre otros. ${ }^{1,2}$ Esta indexación permitirá que la RMH aumente su visibilidad, su impacto, y el acceso a la información publicada desde diversos sitios del mundo, facilitar la localización de revisores par, promover el prestigio de los investigadores y por último y no menos importante, el intercambio entre pares que conduce un mayor desarrollo del campo científico nacional. Por otra parte, la mayoría de estos índices se ha incorporado al movimiento mundial del Acceso Abierto (Open Access en inglés), el cual promulga el acceso gratuito a la información y al uso sin restricciones de los recursos digitales por parte de todas las personas. ${ }^{3}$

Una publicación puede difundirse en acceso abierto si reúne las siguientes condiciones: Es posible acceder a su contenido de manera libre y universal, sin costo alguno para el lector, a través de Internet o cualquier otro medio; El autor o detentor de los derechos de autor otorga a todos los usuarios potenciales, de manera irrevocable y por un periodo de tiempo ilimitado, el derecho de utilizar, copiar o distribuir el contenido, con la única condición de que se dé el debido crédito a su autor; La versión integral del contenido ha sido depositada, en un formato electrónico apropiado, en al menos un repositorio de acceso abierto reconocido internacionalmente como tal y comprometido con el acceso abierto. ${ }^{3}$

El acceso abierto nos ayuda a la diseminación de la investigación académica y a la difusión del conocimiento científico contribuyendo a entender y actuar sobre los problemas de salud nacionales e internacionales. ${ }^{4}$ Sin embargo, eliminar las barreras de acceso a la información para que los usuarios la usen con cualquier propósito, conlleva reconocer el derecho de

Recibido: 23-02-2021 Aceptado 09-03-2021 Primera vez publicado en linea 16-03-2021 Dirigir correspondencia a: Dra. Edna Janeth Maradiaga

Correo electrónico: edjamar3006@yahoo.com

Declaración de relaciones y actividades financieras y no financieras y conflictos de interés: ninguno.

DOl: https://doi.org/10.5377/rmh.v89i1.11580

(c) 2021 Autor(es): (9) (1) atribución de la autoría y el derecho de los autores a mantener la integridad de su trabajo, aunque no siempre esto se cumple ya que el aumento al acceso de la información a través del internet hace más fácil copiar y apropiarse de las ideas de otros sin dar el crédito respectivo, provocando un incremento del plagio intelectual. ${ }^{5}$

Como respuesta a esta situación han surgido una serie de iniciativas como Creative Commons (CC), ${ }^{6}$ que es una organización sin fines de lucro de origen estadounidense que actualmente tiene presencia en múltiples países y que ofrece modelos de licencias que permiten a los autores depositar su obra de forma libre en Internet, limitando los usos que de dicha obra se pueden hacer. Estas licencias permiten determinar concretamente en qué términos pueden utilizarse los trabajos, son gratuitas y no requieren registro, pero todas ellas tienen obligatoriamente que mencionar a la persona autora de la obra (reconocimiento) y llevar un aviso de licencia. Las licencias permiten la reproducción, distribución y la comunicación pública de una obra y sin que haya finalidad comercial, sin obtener beneficio comercial. Para ello utilizan unos atributos que recopilan los distintos usos que se le puede dar a una obra: Reconocimiento/ atribución (BY): El material creado por la autora o el autor puede ser distribuido, copiado y exhibido por terceras personas si se muestra en los créditos; No comercial (NC): el material original y los trabajos derivados pueden ser distribuidos, copiados y exhibidos mientras no tengan usos comerciales (sin beneficio económico); Sin obras derivadas (ND): el material creado por la 0 el artista puede ser distribuido, copiado y exhibido, pero no se puede utilizar para crear un trabajo derivado del original; Compartir por igual (SA): el material modificado puede ser distribuido y modificado manteniendo la misma licencia que el material original. Combinando estos atributos se obtienen las seis licencias Creative Commons que se pueden visualizar combinando los atributos antes mencionados (Ver Figura 1). ${ }^{6}$

En principio, todas las publicaciones que no señalen lo contrario se regirán automáticamente por las leyes de derecho de autor vigente en el país. Hasta recientemente, la RMH manifestaba en la política de publicación en las Instrucciones para Autores, en el apartado 1.3.9 Consentimiento de autor(es) y traspaso de derechos de autor, lo siguiente: El manuscrito debe ser acompañado por la Carta de Solicitud y Consentimiento de Publicación de Artículo firmada por cada autor. "Los derechos 


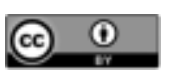

CC BY Reconocimiento: Esta licencia permite a otros distribuir, mezclar, ajustar y construir a partir de su obra, incluso con fines comerciales, siempre que le sea reconocida la autoría de la creación original.

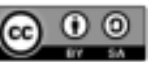

CC BY-SA Reconocimiento-Compartirlgual: Esta licencia permite a otros re-mezclar, modificar y desarrollar sobre su obra incluso para propósitos comerciales, siempre que le atribuyan el crédito y licencien sus nuevas obras bajo idénticos términos.

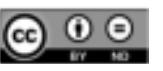

CC BY-ND Reconocimiento-SinObraDerivada: Esta licencia permite la redistribución, comercial y no comercial, siempre y cuando la obra no se modifique y se transmita en su totalidad, reconociendo su autoría.

(7) (3) CC BY-NC Reconocimiento-NoComercial: Esta licencia permite a otros entremezclar, ajustar y construir a partir de su obra con fines no comerciales, y aunque en sus nuevas creaciones deban reconocerle su autoría y no puedan ser utilizadas de manera comercial, no tienen que estar bajo una licencia con los mismos términos.

(1) (3) CC BY-NC-SA Reconocimiento-NoComercial-Compartirlgual: Esta licencia permite a otros entremezclar, ajustar y construir a partir de su obra con fines no comerciales, siempre y cuando le reconozcan la autoría y sus nuevas creaciones estén bajo una licencia con los mismos términos.

cc) (1) $\odot$ CC BY-NC-ND Reconocimiento-NoComercial-SinObraDerivada: Esta licencia es la más restrictiva de las seis licencias principales, sólo permite que otros puedan descargar las obras y compartirlas con otras personas, siempre que se reconozca su autoría, pero no se pueden cambiar de ninguna manera ni se pueden utilizar comercialmente. ${ }^{6}$

Figura 1. Licencias Creative Commons, características e íconos representativos. (Adaptado de Creative Commons Corporation). ${ }^{6}$

de autor son cedidos a la Revista Médica Hondureña. De acuerdo con las leyes de derechos de autor vigentes, si un artículo es aceptado para publicación, los derechos de autor pertenecen a la Revista Médica Hondureña, es decir, que los artículos no pueden ser reproducidos total o parcialmente sin el permiso escrito del Consejo Editorial" 7 Si bien esta es una opción perfectamente válida que autores y editores pueden tomar a la hora de publicar, es necesario considerar otros tipos de licencias de carácter más universal, pensadas para permitir mayor acceso al conocimiento, tener un manejo más flexible en internet y ser reconocidas a nivel internacional, como un compromiso adicional a las leyes locales.

El uso de las licencias Creative Commons es, además, una tendencia global que cada año adquiere más fuerza, ya que importantes organizaciones relacionadas con el mundo de las publicaciones las recomiendan para garantizar la difusión y aprovechamiento del conocimiento humano. Por ejemplo, en diciembre de 2017, el Consejo Latinoamericano de Ciencias Sociales (Clacso), la Red de Revistas Científicas de América Latina y el Caribe, España y Portugal (Redalyc), el Sistema Regional de Información en Línea para Revistas Científicas de América Latina, el Caribe, España y Portugal (conocido como Latindex) y el Instituto Brasileño de Información en Ciencia y Tecnología (IBICT), publicaron una declaración conjunta conocida como la Declaración de México, en la que llaman a la comunidad científica internacional a adoptar una política de acceso abierto en todos los ámbitos de la producción científica, con el fin de expandir el conocimiento y evitar su comercialización indebida. ${ }^{8}$

En cuanto a los derechos de autor, los índices tales como Directorio de Revistas en Acceso Abierto (DOAJ), SCOPUS, REDALYC, Scielo Brasil, y organizaciones como la UNESCO, OPS/OMS y universidades, entre otros, han incorporado entre sus condiciones, que las revistas y los documentos indiquen que tipo de licencia de protección de derechos de autor usan, que además se señale los derechos de terceros sobre las obras producidas y publicadas. ${ }^{9}$ Cada vez más revistas prestigiosas utilizan licencias CC-BY, CC BY NC. Por todo lo anterior, el Consejo Editorial 2021-2022 inició discusiones que han llevado a recomendar que la RMH aplique este tipo de licencias asegurando los derechos autor de los autores que publiquen y al mismo tiempo que permitan a otros copiar, distribuir, y hacer algunos usos de su obra por lo menos de forma no comercial. Además, esto permitiría cumplir con un requisito para la indexación que solicitan las bases de datos internacionales, con lo que aseguraría un mejor posicionamiento de la RMH ante la comunidad científica global.

\section{AGRADECIMIENTO}

Se agradece a la Dra. Cecilia García, Directora de la Biblioteca Médica Nacional, y a la Dra. Jackeline Alger, docente de la Unidad de Investigación Científica, ambas de la Facultad de Ciencias Médicas UNAH, por la revisión crítica del manuscrito.

\section{REFERENCIAS}

1. Alger J. [Editorial]. Revista Médica Hondureña: Aniversario Noventa en tiempos de Pandenia. Rev Méd Hondur. 2020;88(1).

2. Alger J. [Editorial]. Aniversarios y Pandemia de COVID-19: Revista Médica Hondureña, LILACS y la Biblioteca Virtual en Salud De Honduras. Rev Méd Hondur. 2020;88, Supl.No.1

3. Organización de las Naciones Unidas para la Educación, la Ciencia y la Cultura UNESCO. Directrices para Políticas de Desarrollo y Promoción del acceso Abierto. Comunicación e Información [Internet] Recuperado en 19 de febrero 2020]. https://es.unesco.org/openaccess $/ \%$ C2\%BFqu\%C3\%A9-es-acceso-abierto

4. Rodríguez Gallardo, A. Elementos que fundamentan el Acceso Abierto. Investigación bibliotecológica, 2008, 22(44), 161-182. Recuperado en 19 de febrero de 2021, http://www.scielo.org.mx/scielo.php?script=sci_ arttext\&pid=S0187-358X2008000100009\&lng=es\&tIng=es.

5. Astudillo Gómez, F. El Plagio Intelectual, Propiedad Intelectual, vol. V,

núm. 8-9, enero-diciembre, 2006, pp. 242-270. Universidad de los Andes Mérida, Venezuela.

6. Creative Commons Corporation. Comparte tu trabajo. [Internet]. California: Creative Commons; 2020. [consultado 19 de febrero de 2021]. Disponible en: https://creativecommons.org/about/platform/

7. Revista Médica Hondureña. Instrucciones para autores. Rev Méd Hondur. 2020;88(2).

8. Aguado López, E y Becerril-García A. Acceso abierto no comercial y la declaración de México. Amelica. 2020 [Internet]. Recuperado el 19 de febrero 2021. http://amelica.org/index.php/2020/06/12/acceso-abiertono-comercial-y-la-declaracion-de-mexicol

9. Universidad Centroccidental Lisandro Alvarado. Algunas consideraciones sobre la Licencia Creative Commons para Revistas Científicas. Compendium, vol. 19, núm. 37, 2016. https://www.redalyc.org/ jatsRepo/880/88049677001/html/index.html 